\title{
TachoScan PC NET SERVICE digital tachograph equipment
}

\author{
G. Nowacki, I. Mitraszewska \& T. Kamiński \\ Department of Organization and Informatics, \\ Motor Transport Institute, Warsaw, Poland
}

\begin{abstract}
This paper refers to some problems of Digital Tachograph System data to be downloaded and analyzed. Transport firms must download and store two kinds of data in archives: mass memory data and driver card data. This allows a complete record of activities to be obtained for drivers and vehicles. In addition, the digital data offers many opportunities for evaluation to support improved fleet management. The Motor Transport Institute offers the TachoScan solution. The program of analyzing data from digital tachograph and smart cards can generate a driver's general report, which shows distance, working hours, waiting hours and rest hours, start and stop work hours per day for each individual driver. Software supports the data export to Excel, which allows the use of this information in various financial and accounting applications.
\end{abstract}

Keywords: digital tachograph, TachoScan PC NET Service.

\section{Introduction}

A tachograph is an instrument which records driving time; period of work other periods of availability, work breaks and daily rest periods, as well as vehicle speed and distance of the journey. Analogue tachographs, used for 30 years in the European Union countries, have become technically obsolete devices. They do not guarantee effective control of obeying the regimes of driving and resting time by drivers, therefore they are not conducive to actions aiming at improvement of traffic safety. Due to tiredness of drivers, the number of road accidents, people killed and injured the European Commission resolved to implement a high-tech device - a digital tachograph. A digital tachograph 
includes a processing unit, a data memory, a real time clock, two smart card interface devices, a printer, a display, a visual warning, calibration/downloading connector, and facilities for entry of user's inputs. The biggest difference between the current, analogue tachograph and the digital tachograph will be the use of a smart card instead of the record sheets (often called charts, discs, and tachos) used in analogue tachographs. The digital tachograph will now become mandatory on all trucks, of more than 3,5 tons total weight and buses, carrying more than 9 persons, newly registered from 1-th of May 2006 according to Regulation 561/2006 [5]. The implementation of Digital Tachograph System (DTS) now concerns 27 states of the European Union and Island, Liechtenstein, Norway and Switzerland. The implementation of DTS shall concern the signatories of AETR Agreement [1], countries non EU members in Jun $16^{\text {th }}$ 2010 .

\section{Download and evaluation data from DTS}

Based on the regulation of the Council of Europe 2135/98 [3] a concept of the European Digital Tachograph System has arisen as a modern way to increase effectiveness to control the driving time and rest of lorry and bus drivers in order to improve road traffic safety and working conditions. The Council authorized a Committee to prepare the detailed technical specifications. This work was finalized on the $13^{\text {th }}$ June 2002 and the Annex IB was published in the Official Journal of the European Union on the $5^{\text {th }}$ August 2002 [4].

\subsection{Data stored in digital tachograph and cards}

The tachograph's data memory is sufficient to store the information gathered by a tachograph for at least 365 days. The driver's card memory is sufficient for storage of data concerning driver's activities for at least 28 days, but an average driver's speed is defined as 93 changes of activities daily. In case of overfilling of a card memory, like in case of a tachograph, new data replaces chronologically the oldest information. In case of data memory filling up, new data replaces the oldest ones. A registering device stores in an external memory or enables to read (in case of information stored on cards) data divided into six groups:

- General information (VU security certificates, vehicle identification, VU current date and time, type of cards inserted in the VU, all company locks stored, all control records stored),

- Data of driver activities concerning a particular calendar day,

- Events and faults (all faults stored or on-going in the VU, all events except over speeding),

- Detailed data concerning a vehicle speed,

- Technical information (VU data, sensor data, all calibration records stored in VU, RSA signature of data downloaded),

- Data read from cards. 


\subsection{Evaluating data from digital tachograph and cards}

Council Regulation (EC) No 561/2006 and AETR lay down rules on driving times, breaks and rest periods for drivers engaged in the carriage of goods and passengers by road in order to harmonise the conditions of competition between modes of inland transport, especially with regard to the road sector, and to improve working conditions and road safety. The following points shall, in general, be covered by roadside checks:

- Daily and weekly driving times, breaks and daily and weekly rest periods, also the preceding days' record sheets which have to be carried on board the vehicle

- Any cases where the vehicle's authorised speed is exceeded, to be defined as being any periods of more than one minute during which the vehicle's speed exceeds $90 \mathrm{~km} / \mathrm{h}$ for category N3 vehicles or $105 \mathrm{~km} / \mathrm{h}$ for category M3 vehicles,

- Where appropriate, momentary speeds attained by the vehicle as recorded by the recording equipment in no more than the previous 24 hours' use of the vehicle,

- The correct functioning of the recording equipment (determination of possible misuse of the equipment and/or the driver card and/or record sheets) or, where appropriate, presence of the documents.

The duty of data downloading by transport firms is regulated by the Council Regulation No 561/2006. Pursuant to the regulation, transport firms using vehicles covered by the scope of this regulation and equipped with registering devices according to the annex IB to the regulation (EEC) number 3821/85 [2] ensure that all the data entered from a vehicle unit as well as a driver's card have been storied at least for twelve months after its registration and at the request of a control service officer and available directly from the distance or on the territory of the firm. This Regulation also aims to promote improved monitoring and enforcement practices by Member States and improved working practices in the road transport industry.

\section{TachoScan PC NET SERVICE}

Proposition of TachoScan program was developed by PC NET SERVICE in Bielsko-Biała (Poland). TachoScan is a new and precise program used for retrieving, archiving, and analyzing the data from analog tachograph, driver cards and digital tachographs (fig. 1). TachoScan is a tested tool used by over 2600 transport enterprises in Poland. It was favored and is permanently used by the Road Transport Inspection and the Police in Poland, and also by the Police in the Czech Republic and the AAR Inspection in Romania (the equivalent of the Polish Road Transport Inspection). In June 2006, the program received the Motor Transport Institute's recommendation and with it a module for retrieving digital tachograph data was created. It is the only program on the Polish market that comprises the feasibility of retrieving data from traditional analog tachographs as well as from driver cards and digital tachographs, the function of 
archiving the data and its complex and combined analysis. Based on the received data the TachoScan analyses working and resting time and shows all offences and abnormalities. It controls individual and team journey data. It automatically prepares printed statements for the drivers on individual offences. TachoScan program ensures that all data downloaded from both the vehicle unit and driver card are kept for at least 12 months following recording and, should an inspecting officer request it, such data are accessible, either directly or remotely, from the premises of the undertaking.

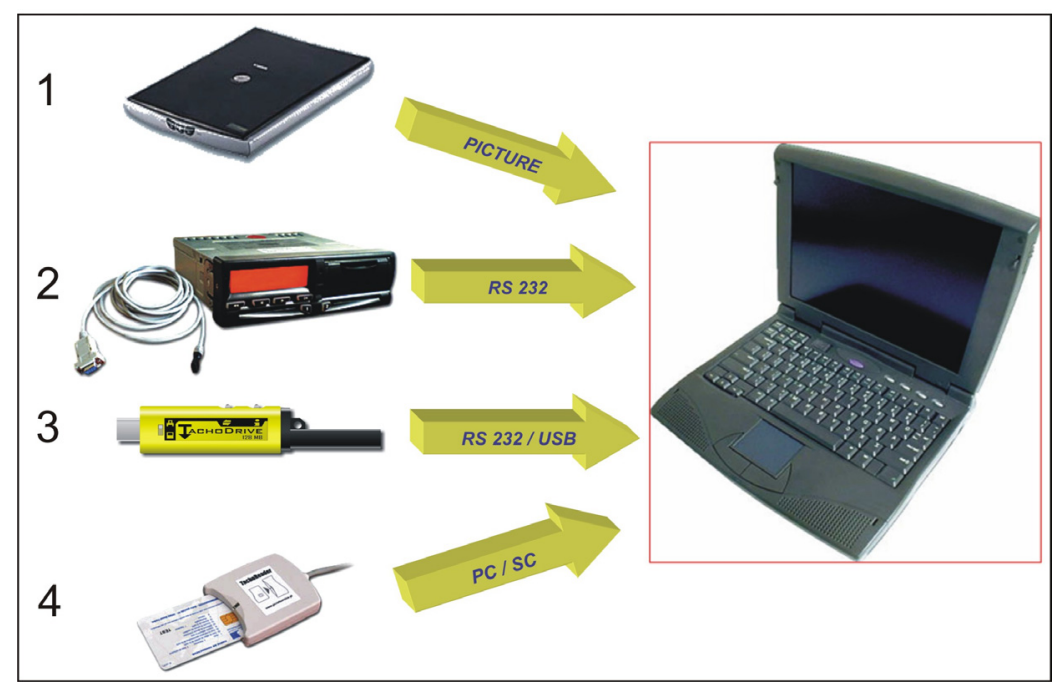

Figure 1: TachoScan PC NET SERVICE digital tachograph equipment.

The program also allows comparing vehicle journeys on specified routes. Advanced Reporting System ensures easy, transparent and permanent control of the drivers' working time, their offences or the working time of a vehicle. Simple and intuitive operating of the program makes it possible not only for the highly computer literate people to be able to work with it, but also for each and every worker of company. At the same time the high quality of the program allows precise and fast data analysis. Using TachoScan solves the problem of retrieving and archiving data, which, according to the Regulation (EC) No 561/2006 of the European Parliament and the Council, is obligatory for each road transport entrepreneur. The program comes complete with full, digital, mini and email digital versions. The full version makes it possible to collect data from analog tachographs, drivers' cards, digital tachographs, and it includes a full report package. Innovations introduced to the program:

- Full handling of collected digital data from card and the tachograph.

- The function of searching for similar or identical surnames of drivers while reading the card.

- The function removing obsolete discs from previous years. 
- Additional information on exceeding the period of 6 days or 56 hours of driving between weekly resting times in the control report.

- The option allowing to check new program versions on the Internet and to download current updates remotely.

- Handling the data collected from other devices of digital tachograph producers (among others D-BOX by Actia, OPTAC by Stoneridge, Downloadkey by Siemens).

- Resting time on ferries and trains, divided by a short driving (entry or exit) is taken in account in control reports.

- Added Canon Lide 60 scanner handling.

The program can download data from digital tachograph and Driver card via a USB port (RS 232) and smart card reader according to standards of PC/SC. Data may be visualized and summed (fig. 2).

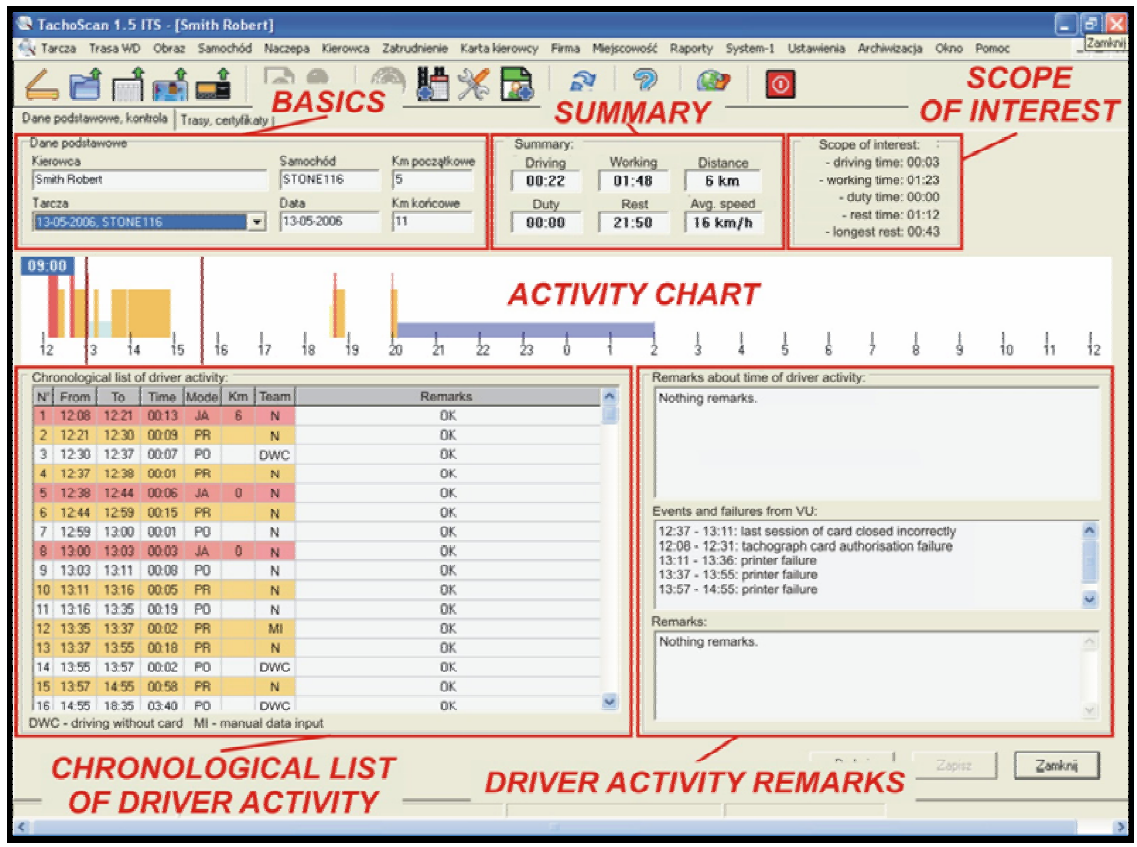

Figure 2: The example of data analysis.

Window of program is divided into visualization areas as follows:

1. Summing of all-out driving time and other work, distance in a given day, all time of duty, rest period and the average speed limit.

2. Time of driver activity in marked fragment of area 5 .

3. Remarks generated by program and events, failures registered by VU.

4. Chronological list of driver activity (time of beginning and the end, activity duration time, road distance, information of single work or team work).

5. Diagram of daily driver activities. 


\section{Recapitulation}

Implementation of Digital Tachograph System for the Republic of Poland, as well as for many other Member Sates of the EU, constitutes an enterprise which is complex and difficult to realize. It requires many different actions coordinated not only on the state but also on the international level. Implementation of DTS will cause an increased opportunity to enforce law in relation to drivers and traders of a road transport, which will largely contribute to improvement of a traffic safety, but at the same time, can rationalize functioning of transport firms.

The program of analyzing data from digital tachograph and smart cards can generate drivers general report showing distance, work hours, waiting hours and rest hours, start and stop work hours per day for individual driver. Software supports the data export to Excel, which allows using this information in various financial and accounting applications. Vehicles reports can be generated from the Database (Vehicles Activity Report, Vehicles Notifications Report, Vehicles Faults Report, Vehicles Events Report, Vehicles Places Report, Vehicles Distances Report, Vehicles Speed Report, and Vehicles Usage Report).

\section{References}

[1] AETR - European Agreement concerning the Work of Crews of Vehicles engaged in the International Road Transport), Geneva, 1 July 1970, (it was approved 5 January 1976).

[2] Council Regulation (EEC) No 3821/85 of 20 $0^{\text {th }}$ December 1985 on recording equipment in road transport (also called 'Analogue Tachograph'). The Official Journal of the European Union, L 370, 31 December 1985.

[3] Council Regulation (EC) No $2135 / 98$ of $24^{\text {th }}$ September 1998 amending Regulation (EEC) $n^{\circ} 3821 / 85$ on recording equipment in road transport and Directive 88/599/EEC concerning the application of Regulations (EEC) $\mathrm{n}^{\circ} 3820 / 84$ and (EEC) $\mathrm{n}^{\circ} 3821 / 85$ (also called 'Digital Tachograph'). The Official Journal of the European Union, L 274, 9 October 1998.

[4] Council Regulation (EC) No 1360/2002 of $13^{\text {th }}$ June 2002 adapting for the seventh time to technical progress Council Regulation (EEC) $\mathrm{n}^{\circ} 3821 / 85$ on recording equipment in road transport (also called 'Technical Specifications of Digital Tachograph'). The Official Journal of the European Union, L 207, 5 August 2002.

[5] Council Regulation (EC) No 561/2006 of $15^{\text {th }}$ March on the Harmonization of certain social legislation relating to road transport and amending Council Regulations (EEC) $\mathrm{N}^{\circ} 3821 / 85$ and (EC) $\mathrm{N}^{\circ}$ 2135/98 and repealing Council Regulation (EEC) $N^{\circ} 3820 / 85$. The Official Journal of the European Union, 11 April 2006. 